\title{
Aplikasi Software FLO-2D untuk Pembuatan Peta Genangan DAS Guring, Banjarmasin
}

\author{
Devy Amalia dan Umboro Lasminto \\ Jurusan Teknik Sipil, Fakultas Teknik Sipil dan Perencanaan, Institut Teknologi Sepuluh Nopember (ITS) \\ Jl. Arief Rahman Hakim, Surabaya 60111 Indonesia \\ e-mail: devyamalia17@gmail.com,umboro_hydro@yahoo.com
}

\begin{abstract}
Abstrak - Genangan adalah peristiwa yang terjadi ketika aliran air yang berlebihan merendam daratan. Dikarenakan dampak yang diberikan genangan memerlukan biaya cukup besar untuk rehabilitasi maka perlu adanya sistem pemodelan genangan menggunakan komputer di suatu kota untuk mengetahui sebaran titik - titik yang berpotensi tinggi terjadi genangan. FLO - 2D merupakan model penelusuran genangan yang mensimulasikan aliran saluran dan aliran permukaan bebas yang mampu menggabungkan komponen 1 dimesi (1D) dan 2 dimensi (2D) untuk mendapatkan informasi kedalaman genangan serta memfokuskan pada pemetaan genangan sungai maupun genangan air permukaan. Sungai Guring, sebagai salah satu sungai yang berada pada Banjarmasin Tengah, digunakan sebagai objek studi dalam simulasi Flo-2D ini.

Dalam penelitian ini, dilakukan analisis peta menggunakan data peta topografi untuk menentukan batas DAS Guring. Analisis hidrologi menggunakan data curah hujan untuk mendapatkan hujan rencana dan hidrograf inflow. Analisis hidrolika menggunakan data penampang sungai existing. Hasil dari analisis tersebut akan dimasukkan kedalam program FLO2D sebagai input data.

Terdapat 5 alternatif pemodelan yang dapat dilakukan menggunakan data yang diperoleh yakni: Pemodelan 1, menggunakan data hujan ; Pemodelan 2, menggunakan data hujan, penampang saluran, dan tanpa data pasang surut ; Pemodelan 3, menggunakan data hujan, penampang saluran, dan dengan data pasang surut ; Pemodelan 4, menggunakan hidrograf inflow, penampang saluran, dan tanpa data pasang surut ; Pemodelan 5, menggunakan hidrograf inflow, penampang saluran, dan dengan data pasang surut. Berdasarkan hasil proses simulasi FLO-2D, pemodelan 3 merupakan pemodelan yang paling cocok dijadikan sebagai peta genangan DAS Guring karena menghasilkan plot grid element maximum flow velocity dan bentuk grafik maximum water surface elevation yang realistis dengan menggambarkan adanya pengaruh pasang surut dan tidak adanya pengaruh boundary hulu dan hilir. Mayoritas pemodelan memiliki kedalaman maksimum genangan yang terkonsentrasi pada sungai/saluran.
\end{abstract}

Kata kunci-DAS Guring, FLO-2D Software, Peta Genangan

\section{PENDAHULUAN}

$\mathrm{G}$ ENANGAN_adalah peristiwa yang terjadi ketika aliran air yang berlebihan merendam daratan. Salah satu penyebab genangan adalah perubahan fungsi lahan. Kota Banjarmasin misalnya, seiring dengan meningkatnya laju pertumbuhan penduduk dan aktivitasnya, kualitas sungai secara fisik mulai terus mengalami penurunan. Beberapa anak sungai, seperti Sungai Guring (sungai yang berada pada Banjarmasin Tengah), kurang berfungsi akibat endapan lumpur, sampah dan gulma yang menutup anak sungai karena adanya pemukiman liar di bantaran sungai sehingga aliran kurang lancar dan daya resapan air berkurang sehingga menyebabkan terjadinya potensi genangan. Genangan yang terjadi, mengakibatkan kerusakan fisik secara permanen maupun temporal di beberapa infrastruktur pendukung.

Dikarenakan dampak yang diberikan genangan memerlukan biaya cukup besar untuk rehabilitasi, maka perlu adanya sistem pemodelan genangan menggunakan komputer di suatu kota untuk mengetahui sebaran titik yang berpotensi tinggi terjadi genangan. FLO - 2D merupakan model penelusuran genangan yang mensimulasikan aliran saluran dan aliran permukaan bebas dalam topografi yang kompleks ${ }^{[1]}$. FLO 2D menggabungkan komponen 1D dan 2D untuk mendapatkan informasi kedalaman genangan dan memfokuskan pada pemetaan genangan sungai maupun genangan air permukaan. Pemodelan genangan menggunakan 2D mampu mengukur kedalaman, kecepatan, dan arah arus genangan di sepanjang dataran genangan.

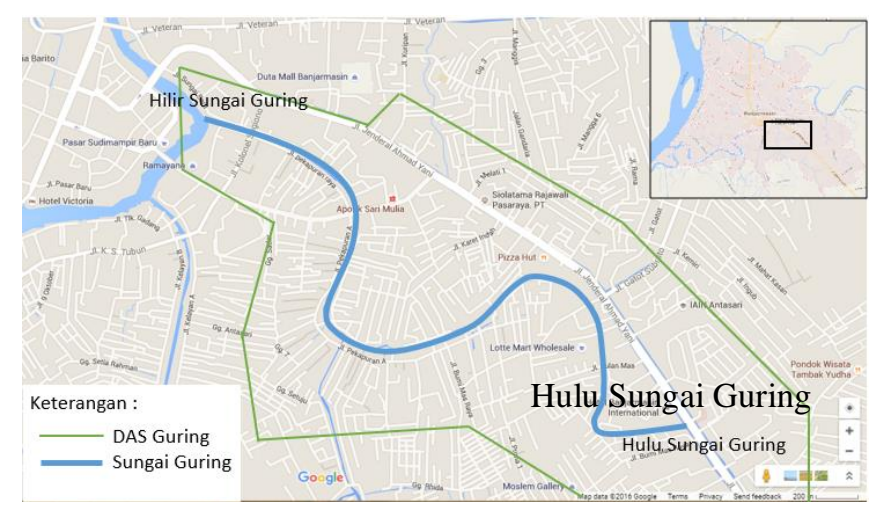

Gambar 1. Lokasi Studi Sungai Guring

Sumber : Google Maps

Berikut rumusan masalah yang didapatkan dari latar belakang yang telah disebut diatas :

1. Bagaimana pendekatan pemodelan aliran 2D dalam software Flo-2D?

2. Bagaimana alternatif permodelan aliran 2D dengan software Flo-2D?

3. Bagaimana perbandingan hasil alternatif pemodelan aliran dengan Flo-2D?

4. Bagaimana menampilkan hasil permodelan 2D dan menggunakannya untuk membuat peta genangan DAS Guring?

Batasan masalah dalam pengerjaan penelitian ini adalah sebagai berikut : 
1. Tidak memperhitungkan angkutan sedimen Sungai Guring

2. Tidak memperhitungkan drainase kawasan perumahan pada DAS Guring

\section{METODOLOGI}

Metodologi yang digunakan dalam pemodelan peta genangan Flo-2D adalah sebagai berikut:

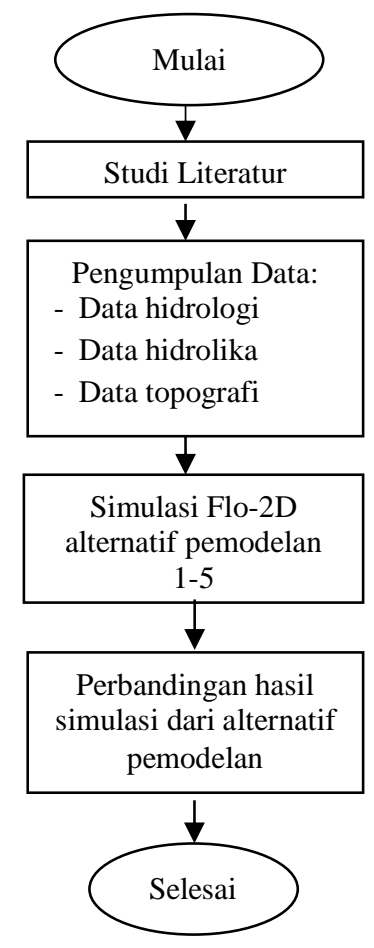

Gambar 2. Diagram Alir Metodologi

\section{HASIL DAN PEMBAHASAN}

\section{A. Data Input}

Sebelum melakukan simulasi Flo-2D, perlu adanya mengolah data input terlebih dahulu yang terdiri dari:

1. Data hidrologi

Dikarenakan data hidrologi yang didapat masih dalam nilai hujan maksimum harian, maka data tersebut harus diolah terlebih dahulu menjadi hujan rencana dan hidrograf inflow ${ }^{[2]-[4]}$, sebelum dimasukkan kedalam pemodelan Flo-2D. Adapun hasil perhitungan hujan rencana menggunakan distribusi log pearson tipe III ditampilkan dalam tabel 1, sedangkan hidrograf inflow menggunakan metode hidrograf sintetis nakayasu ditampilkan pada gambar 3 dan tabel 2 .

Tabel 1.

Nilai Hujan Rencana Periode Ulang T

\begin{tabular}{|c|c|c|c|c|}
\hline periode ulang & $\mathrm{k}$ & $\log \mathrm{R}_{\mathrm{t}}$ & $\mathrm{R}_{\mathrm{t}}$ & Satuan \\
\hline $\mathrm{R}_{2}$ & -0.319 & 1.821 & 66.215 & $\mathrm{~mm}$ \\
\hline $\mathrm{R}_{5}$ & 0.592 & 2.028 & 106.572 & $\mathrm{~mm}$ \\
\hline $\mathrm{R}_{10}$ & 1.294 & 2.187 & 153.784 & $\mathrm{~mm}$ \\
\hline $\mathrm{R}_{25}$ & 2.23 & 2.399 & 250.767 & $\mathrm{~mm}$ \\
\hline $\mathrm{R}_{50}$ & 2.942 & 2.561 & 363.753 & $\mathrm{~mm}$ \\
\hline $\mathrm{R}_{100}$ & 3.656 & 2.723 & 528.2 & $\mathrm{~mm}$ \\
\hline
\end{tabular}

Sumber : hasil perhitungan
Hidrograf Banjir Rancangan Nakayasu Periode Ulang 10 Tahun

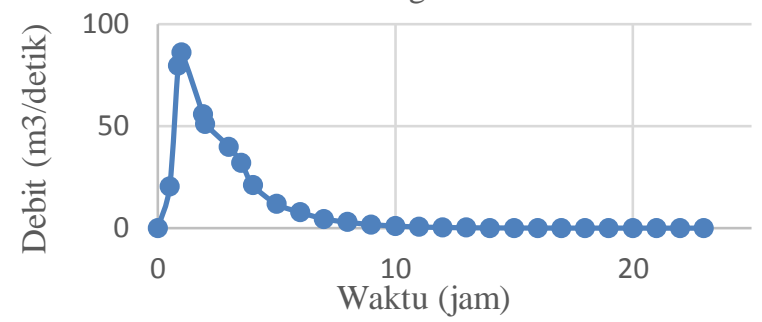

Gambar 3. Hidrograf Banjir Rancangan Nakayasu Periode Ulang 10 Tahun

Tabel 2.

Perhitungan Hidrograf Banjir Rancangan Nakayasu Periode Ulang 10 Tahun

\begin{tabular}{|c|c|c|c|c|c|c|c|c|}
\hline \multirow{2}{*}{ Jam } & \multirow{2}{*}{$\begin{array}{c}\mathrm{HSS} \\
\mathrm{m} 3 / \mathrm{dtk}\end{array}$} & \multicolumn{6}{|c|}{ Curah Hujan } & \multirow{2}{*}{$\begin{array}{c}\text { Debit } \\
\mathrm{m} 3 / \mathrm{dtk}\end{array}$} \\
\hline & & 84.63 & 22.00 & 15.43 & 12.28 & 10.37 & 9.07 & \\
\hline (1) & (2) & (3) & (4) & (5) & (6) & (7) & (8) & (9) \\
\hline 0 & 0 & 0 & & & & & & 0 \\
\hline 0.5 & 0.242 & 20.506 & 0 & & & & & 20.506 \\
\hline 0.854 & 0.877 & 74.200 & 5.330 & 0 & & & & 79.530 \\
\hline 1 & 0.744 & 62.972 & 19.286 & 3.739 & 0 & & & 85.997 \\
\hline 1.9 & 0.270 & 22.832 & 16.368 & 13.529 & 2.976 & 0 & & 55.705 \\
\hline 2 & 0.241 & 20.398 & 5.935 & 11.482 & 10.770 & 2.514 & 0 & 51.098 \\
\hline 3 & 0.117 & 9.905 & 5.302 & 4.163 & 9.141 & 9.095 & 2.197 & 39.803 \\
\hline 3.52 & 0.079 & 6.701 & 2.575 & 3.719 & 3.314 & 7.719 & 7.950 & 31.978 \\
\hline 4 & 0.060 & 5.108 & 1.742 & 1.806 & 2.961 & 2.799 & 6.747 & 21.163 \\
\hline 5 & 0.034 & 2.907 & 1.328 & 1.222 & 1.438 & 2.500 & 2.446 & 11.841 \\
\hline 6 & 0.020 & 1.655 & 0.756 & 0.931 & 0.973 & 1.214 & 2.186 & 7.714 \\
\hline 7 & 0.011 & 0.942 & 0.430 & 0.530 & 0.741 & 0.821 & 1.061 & 4.526 \\
\hline 8 & 0.006 & 0.536 & 0.245 & 0.302 & 0.422 & 0.626 & 0.718 & 2.849 \\
\hline 9 & 0.004 & 0.305 & 0.139 & 0.172 & 0.240 & 0.356 & 0.547 & 1.760 \\
\hline 10 & 0.002 & 0.174 & 0.079 & 0.098 & 0.137 & 0.203 & 0.312 & 1.002 \\
\hline 11 & 0.001 & 0.099 & 0.045 & 0.056 & 0.078 & 0.115 & 0.177 & 0.570 \\
\hline 12 & 0.001 & 0.056 & 0.026 & 0.032 & 0.044 & 0.066 & 0.101 & 0.324 \\
\hline 13 & 0.000 & 0.032 & 0.015 & 0.018 & 0.025 & 0.037 & 0.057 & 0.185 \\
\hline 14 & 0.000 & 0.018 & 0.008 & 0.010 & 0.014 & 0.021 & 0.033 & 0.105 \\
\hline 15 & 0.000 & 0.010 & 0.005 & 0.006 & 0.008 & 0.012 & 0.019 & 0.060 \\
\hline 16 & 0.000 & 0.006 & 0.003 & 0.003 & 0.005 & 0.007 & 0.011 & 0.034 \\
\hline 17 & 0.000 & 0.003 & 0.002 & 0.002 & 0.003 & 0.004 & 0.006 & 0.019 \\
\hline 18 & 0.000 & 0.002 & 0.001 & 0.001 & 0.002 & 0.002 & 0.003 & 0.011 \\
\hline 19 & 0.000 & 0.001 & 0.000 & 0.001 & 0.001 & 0.001 & 0.002 & 0.006 \\
\hline 20 & 0.000 & 0.001 & 0.000 & 0.000 & 0.000 & 0.001 & 0.001 & 0.004 \\
\hline 21 & 0.000 & 0.000 & 0.000 & 0.000 & 0.000 & 0.000 & 0.001 & 0.002 \\
\hline 22 & 0.000 & 0.000 & 0.000 & 0.000 & 0.000 & 0.000 & 0.000 & 0.001 \\
\hline 23 & 0.000 & 0.000 & 0.000 & 0.000 & 0.000 & 0.000 & 0.000 & 0.001 \\
\hline
\end{tabular}

2. Data hidrolika

Tabel 3.

Dimensi Penampang Rectangular Sungai

\begin{tabular}{|c|c|c|c|c|c|c|c|}
\hline Section & area (m2) & depth (m) & width (m) & Section & area (m2) & depth (m) & width (m) \\
\hline G 0 & 7.3115 & 2 & 3.66 & G 15 & 20.8915 & 2 & 10.45 \\
\hline G 1 & 7.9383 & 2 & 3.97 & G 16 & 15.7703 & 2 & 7.89 \\
\hline G 2 & 7.8514 & 2 & 3.93 & G 17 & 10.487 & 2 & 5.24 \\
\hline G 3 & 9.9932 & 2 & 5.00 & G 18 & 19.713 & 2 & 9.86 \\
\hline G 4 & 12.062 & 2 & 6.03 & G 19 & 30.3978 & 2 & 15.20 \\
\hline G 5 & 15.0276 & 2 & 7.51 & G 20 & 31.8865 & 2 & 15.94 \\
\hline G 6 & 12.2745 & 2 & 6.14 & G 21 & 18.588 & 2 & 9.29 \\
\hline G 7 & 10.02 & 2 & 5.01 & G 22 & 32.7684 & 2 & 16.38 \\
\hline G 8 & 13.375 & 2 & 6.69 & G 23 & 18.2552 & 2 & 9.13 \\
\hline G 9 & 23.025 & 2 & 11.51 & G 24 & 32.488 & 2 & 16.24 \\
\hline G 10 & 19.3655 & 2 & 9.68 & G 25 & 34.9741 & 2 & 17.49 \\
\hline G 11 & 27.4915 & 2 & 13.75 & G 26 & 20.0784 & 2 & 10.04 \\
\hline G 12 & 32.653 & 2 & 16.33 & G 27 & 31.6741 & 2 & 15.84 \\
\hline G 13 & 16.642 & 2 & 8.32 & G 28 & 47.115 & 2 & 23.56 \\
\hline G 14 & 16.466 & 2 & 8.23 & G 29 & 43.26 & 2 & 21.63 \\
\hline
\end{tabular}

Sumber: hasil perhitungan

Data hidrolika yang didapatkan menggambarkan kondisi eksisting keadaan sungai Guring. Dikarenakan input sungai 
nantinya dalam bentuk segi-4 (rectangular), yang berbeda dari bentuk eksisting penampang sungai, maka perlu adanya perhitungan luas penampang dari kondisi eksisting untuk penyesuaian dimensi ke-dalam bentuk segi-4. Adapun hasil analisis perhitungan penampang baru berbentuk segi-4 ditampilkan pada Tabel 3 .

\section{B. Simulasi Model}

Pemodelan yang dilakukan, menggunakan data peta topografi, hujan rencana, hidrograf inflow, dan penampang sungai, dalam GDS adalah :

1. Pemodelan menggunakan data hujan (pemodelan 1)

2. Pemodelan menggunakan data hujan, penampang saluran, dan tanpa data pasang surut (pemodelan 2)

3. Pemodelan menggunakan data hujan, penampang saluran, dan dengan data pasang surut (pemodelan 3)

4. Pemodelan menggunakan hidrograf inflow, penampang saluran, dan tanpa data pasang surut (pemodelan 4)

5. Pemodelan menggunakan hidrograf inflow, penampang saluran, dan dengan data pasang surut (pemodelan 5)

Adapun tahapan pemodelan secara keseluruhan ${ }^{[5]}$, dibagi menjadi 5 tahapan yakni :

1. Input data topografi

Pada tahapan ini penting untuk menentukan Daerah Aliran Sungai (DAS) Guring. DAS tersebut dijadikan computational area selama proses simulasi berlangsung. Didalam computational area, terdapat grid-grid yang dibuat untuk memudahkan dalam proses simulasi program. Grid tersebut berisikan data nomer grid, titik elevasi, dan nilai nmanning. Data topografi dapat berupa file format .dxf, .pts, ataupun .asc.

2. Input data hidrolika

Tahap ini dilakukan setelah Output File Formats data topografi telah terbuat. Variabel yang harus dimasukkan dalam input data hidrolika penampang segi-4 pada Flo-2D channel geometry adalah, lebar dan kedalaman saluran, serta elemen grid dari right bank channel.

3. Input data hidrologi

Input data hidrologi dilakukan setelah Output File Formats data topografi terbuat untuk pemodelan 1, dan data topografi+channel untuk pemodelan 2 sampai 5. Masingmasing pemodelan pada tahapan ini memiliki langkah berbeda-beda, yang akan dijelaskan secara singkat sebagai berikut:

Pemodelan 1 dan 2: masukkan data hujan rencana $\mathrm{R}_{25}$, karena ada kemungkinan simulasi tidak berjalan selama 24 jam, sehingga hujan tidak turun sebesar $100 \%$.

Pemodelan 3: masukkan data hujan seperti pemodelan 1 dan 2. Namun, ditambah input data pasang surut pada elemen outflow, yakni pada hilir sungai Guring, elevasi terendah.

Pemodelan 4: masukkan data hidrograf inflow pada bagian hulu sungai.

Pemodelan 5: masukkan data hidrograf inflow seperti pemodelan 4. Namun, ditambah input data pasang surut pada elemen outflow, yakni pada hilir sungai Guring, elevasi terendah.

4. Melakukan simulasi

Simulasi pemodelan dilakukan dengan simulation time $=6$ jam dan tampilan output interval $=0.5$ jam dalam semua alternatif pemodelan.
5. Menampilkan hasil simulasi

Hasil simulasi pemodelan 1 - 5 ditampilkan menggunakan program post-processor Flo-2D Mapper. Hasil tersebut berupa peta kedalaman genangan, nilai dan arah dari kecepatan aliran genangan, serta peta potensi bahaya (hazard map) ${ }^{[6]}$. Untuk melihat hasil pemetaan kedalaman maksimum genangan channel dan floodplain dari kelima pemodelan dapat dilihat secara berturut-turut pada gambar 4 sampai gambar 8 . Nilai kedalaman maksimum aliran atau genangan, ditampilkan melalui skala warna.

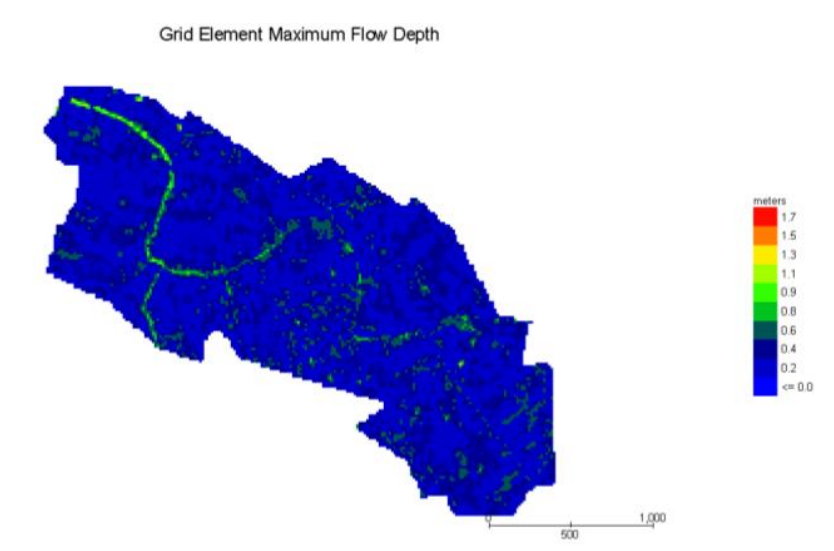

Gambar 4. Plot Maximum Flow Depth Pemodelan 1

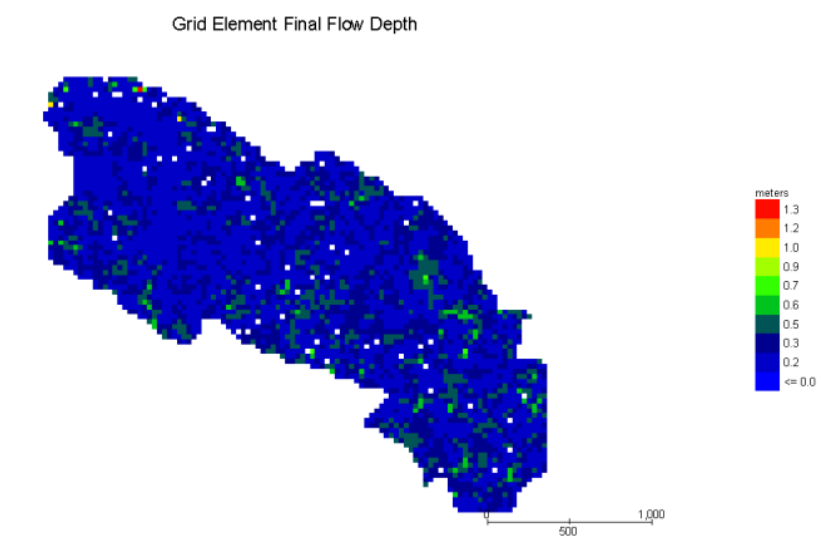

Gambar 5. Plot Maximum Flow Depth Pemodelan 2

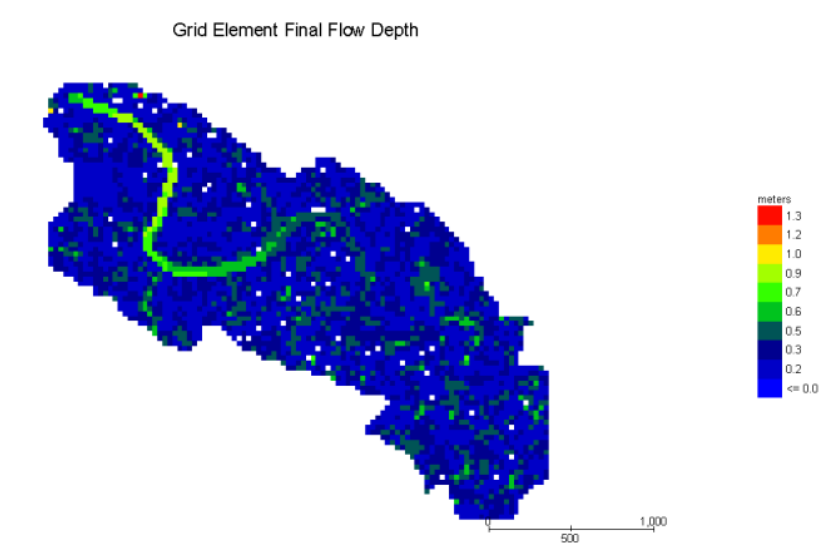

Gambar 6. Plot Maximum Flow Depth Pemodelan 3 
Grid Element Final Flow Depth

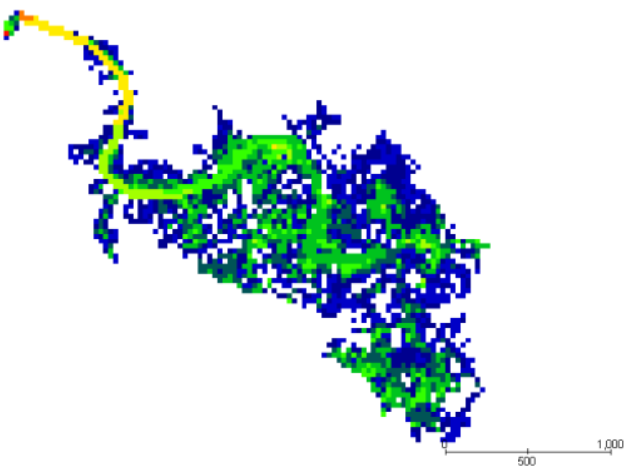

Gambar 7. Plot Maximum Flow Depth Pemodelan 4 Grid Element Final Flow Depth

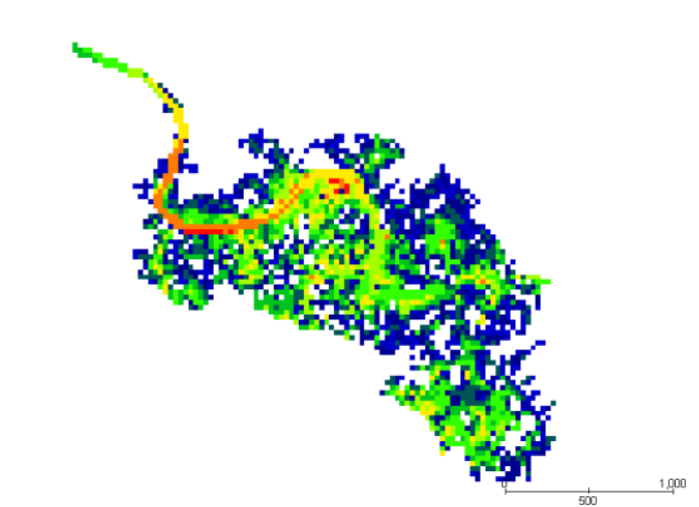

Gambar 8. Plot Maximum Flow Depth Pemodelan 5

Sedangkan untuk melihat hasil plotting kecepatan maksimum floodplain (vector) dalam program Mapper dari kelima pemodelan secara berturut-turut, ditampilkan pada gambar 9 sampai gambar 13. Besaran arah dan nilai kecepatan aliran, ditampilkan melalui gambar panah berskala warna, yang berada disisi kanan gambar. Grid Element Maximum Velocity

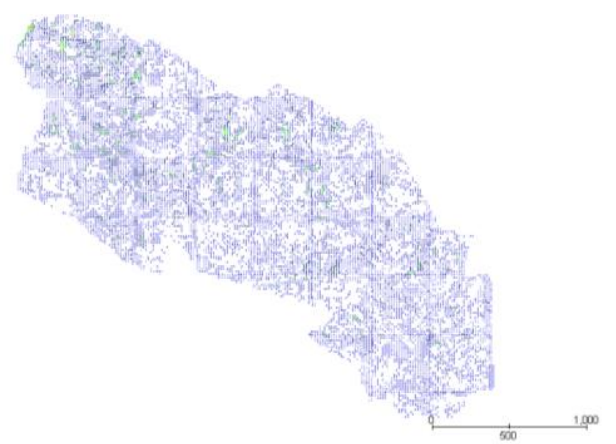

Gambar 9. Plot max velocity (vector) Pemodelan 1 Grid Element Maximum Velocity

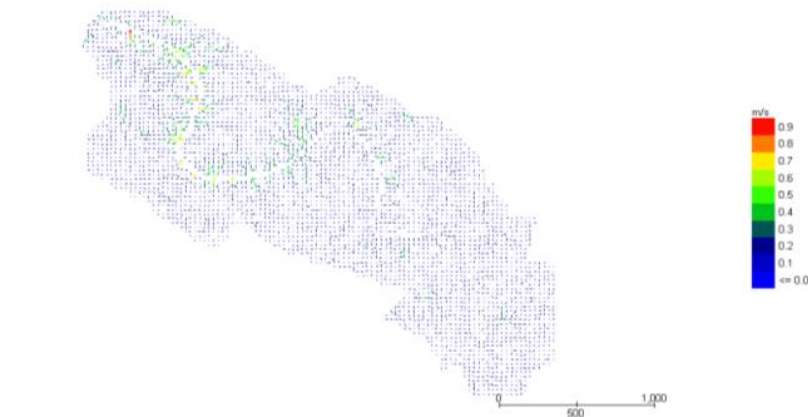

Gambar 10. Plot max velocity (vector) Pemodelan 2
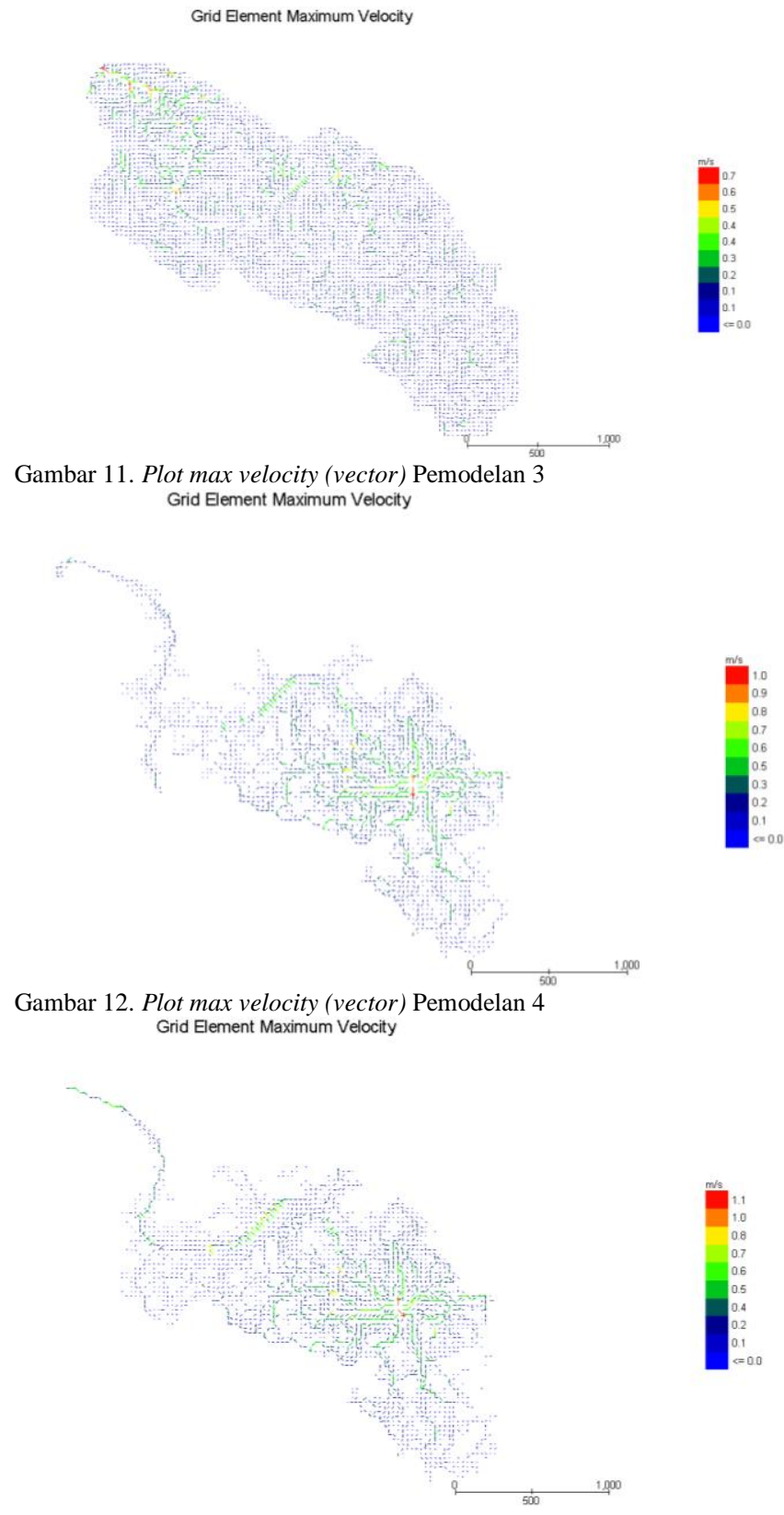

Gambar 13. Plot max velocity (vector) Pemodelan 5

Gambar 4-13, didapatkan beberapa informasi terkait kedalaman maksimum genangan dan nilai serta arah dari kecepatan aliran untuk tiap pemodelan, yakni :

Pemodelan 1, mensimulasikan aliran permukaan bebas saja, daerah hilir sungai merupakan kawasan paling tergenang dengan sebagian besar kedalaman genangan berkisar antara 0 1 meter dan kecepatan tertinggi bernilai $0-0.6 \mathrm{~m} / \mathrm{s}$, serta arah aliran normal, menuju ke arah elemen outflow/hilir sungai.

Pemodelan 2, mensimulasikan aliran permukaan bebas dan aliran saluran, sebaran genangan merata dengan kedalaman berkisar antara $0-0.5$ meter dan kecepatan tertinggi berada pada kawasan hilir dengan nilai $0-0.3 \mathrm{~m} / \mathrm{s}$, namun ada beberapa titik yang memiliki kecepatan $0.7 \mathrm{~m} / \mathrm{s}$. Kecepatan maksimum aliran dalam sungai $=1.5 \mathrm{~m} / \mathrm{s}$ dan arah aliran normal, menuju ke arah elemen outflow/hilir sungai.

Pemodelan 3, mensimulasikan aliran permukaan bebas dan aliran saluran, daerah hilir sungai merupakan kawasan paling tergenang dengan kedalaman berkisar antara $0-0.9$ meter dan 
kecepatan tertinggi berada pada kawasan hilir dengan nilai 0 $0.4 \mathrm{~m} / \mathrm{s}$, namun ada beberapa titik yang memiliki kecepatan 0.7 $\mathrm{m} / \mathrm{s}$. Kecepatan maksimum aliran dalam sungai $=3.5 \mathrm{~m} / \mathrm{s}$ pada bagian hilir/muara dan arah aliran normal, menuju ke arah elemen outflow/hilir sungai.

Pemodelan 4, mensimulasikan aliran permukaan bebas dan aliran saluran, genangan terkonsentrasi pada daerah hulu, baik saluran maupun floodplain, dengan kedalaman $0-0.8$ meter. Meskipun begitu, daerah hilir sungai tetap menjadi kawasan genangan terdalam dengan nilai 0.8 - 1 meter dan berada pada daerah saluran. Kecepatan tertinggi berada pada kawasan hilir dengan nilai $0-0.7 \mathrm{~m} / \mathrm{s}$, namun ada beberapa titik yang memiliki kecepatan mencapai $1 \mathrm{~m} / \mathrm{s}$. Kecepatan maksimum aliran dalam sungai $=1.4 \mathrm{~m} / \mathrm{s}$ pada bagian daerah hulu dan arah aliran normal, menuju ke arah elemen outflow/hilir sungai.

Pemodelan 5, mensimulasikan aliran permukaan bebas dan aliran saluran, genangan terkonsentrasi pada daerah hulu, baik saluran maupun floodplain, dengan sebagian besar kedalaman berkisar antara $0.4-0.8$ meter. Kecepatan tertinggi berada pada kawasan hilir dengan nilai $0-0.7 \mathrm{~m} / \mathrm{s}$, namun ada beberapa titik yang memiliki kecepatan mencapai $1.1 \mathrm{~m} / \mathrm{s}$. Kecepatan maksimum aliran dalam sungai $=3.5 \mathrm{~m} / \mathrm{s}$ pada bagian hilir/muara dan arah aliran normal, menuju ke arah elemen outflow/hilir sungai.

Hasil hazard map pada tiap pemodelan secara berturut-turut ditampilkan gambar 14 sampai gambar 18. Warna dari hazard map diterjemahkan ke dalam daerah potensi bahaya tertentu seperti yang ditunjukkan pada tabel 4 . Kemudian, batas ambang kedalaman aliran dan kecepatan mengikuti seleksi yang telah diberikan $^{[6]}$ dari program Mapper seperti yang ditunjukkan pada tabel 5 .

Tabel 4.

Definisi Warna Hazard map

\begin{tabular}{|c|c|l|}
\hline \multicolumn{3}{|c|}{ FLOOD HAZARD DEFINITION } \\
\hline Hazard Level & Map color & \multicolumn{1}{c|}{ Description } \\
\hline High & Red & $\begin{array}{l}\text { Persons are in danger both inside and outside their houses. } \\
\text { Structures are in danger of being destroyed. }\end{array}$ \\
\hline Medium & Orange & $\begin{array}{l}\text { Persons are in danger outside their houses. Buildings may } \\
\text { suffer damage and possible destruction depending on } \\
\text { construction characteristics. }\end{array}$ \\
\hline Low & Yellow & $\begin{array}{l}\text { Danger to persons is low or non-existent. Buildings may } \\
\text { suffer little damages, but flooding or sedimentation may } \\
\text { affect structure interiors. }\end{array}$ \\
\hline
\end{tabular}

Tabel 5.

Definisi Intensitas Banjir

\begin{tabular}{||c|c|c|c||}
\hline \hline \multicolumn{5}{|c||}{ DEFINITION OF WATER FLOOD INTENSITY } \\
\hline Flood Intensity & Maximum depth $\mathrm{h}(\mathrm{m})$ & & $\begin{array}{c}\text { Product of maximum depth h times } \\
\left.\text { maximum velocity v } \mathrm{m}^{2} / \mathrm{s}\right)\end{array}$ \\
\hline High & $\mathrm{h}>1.5 \mathrm{~m}$ & OR & $\begin{array}{r}\mathrm{h}>1.5 \mathrm{~m}^{2} / \mathrm{s} \\
\hline \text { Medium }\end{array}$ \\
\hline Low & $0.5 \mathrm{~m}<\mathrm{h}<1.5 \mathrm{~m}$ & OR & $0.5 \mathrm{~m}^{2} / \mathrm{s}<\mathrm{v} \mathrm{h}<1.5 \mathrm{~m}^{2} / \mathrm{s}$ \\
\hline
\end{tabular}

Sumber: Mapper Manual 2009

Hazard Map
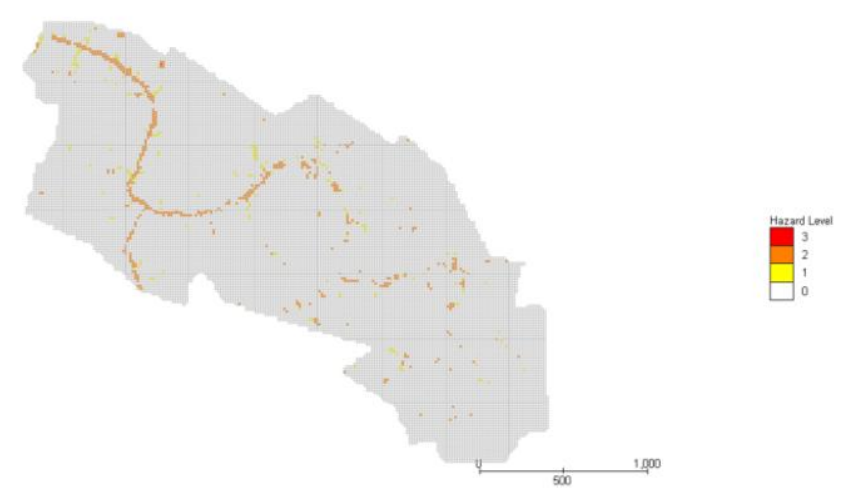

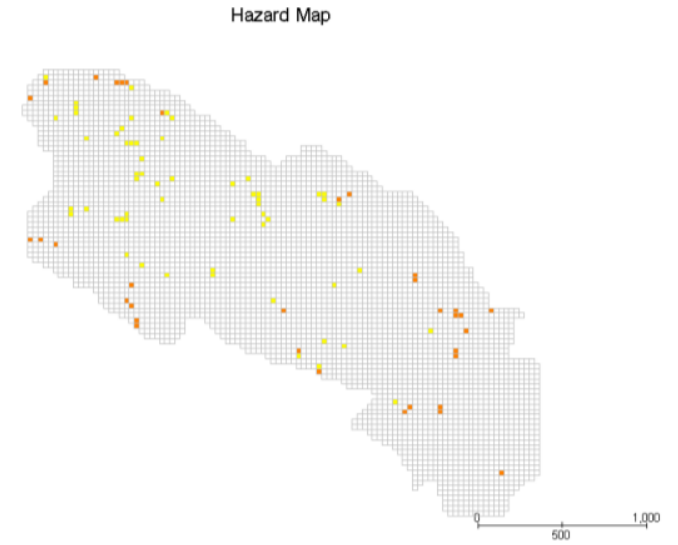

Gambar 15. Hazard map Pemodelan 2 Hazard Map

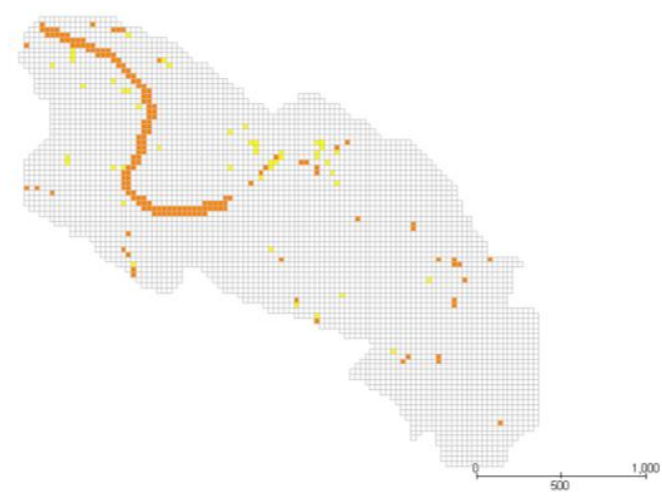

Gambar 16. Hazard map Pemodelan 3 Hazard Map

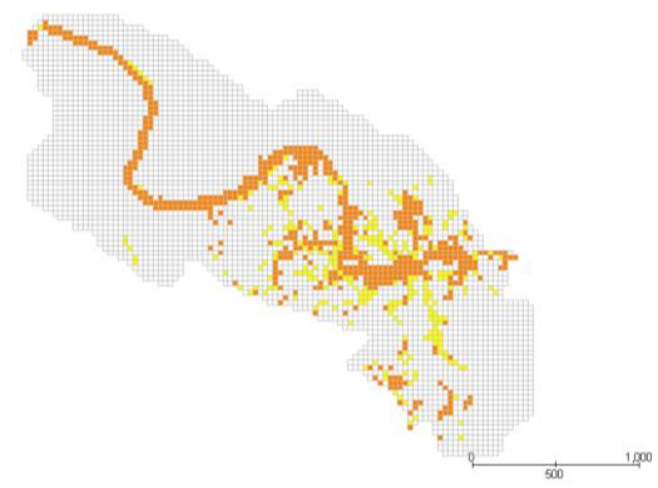

Gambar 17. Hazard map Pemodelan 4 Hazard Map

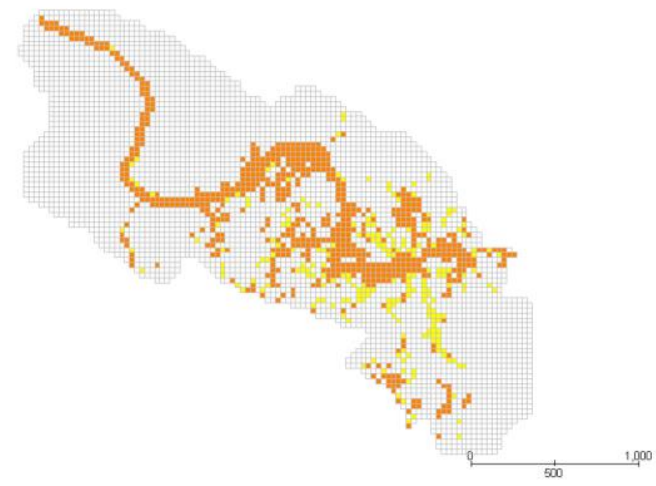

Gambar 18. Hazard map Pemodelan 5

Gambar 14. Hazard map Pemodelan 1 


\section{KESIMPULAN DAN SARAN}

\section{A. KESIMPULAN}

1. Pendekatan pemodelan aliran 2D dalam software Flo-2D adalah menggabungkan langkah-langkah berikut ${ }^{[7]}$ :

- DAS dimodelkan dengan membagi wilayahnya menjadi grid-grid, yang ukurannya sesuai kebutuhan (umumnya 5-100 meter), berfungsi sebagai computational domain dan berisi informasi nomer grid, elevasi dari peta topografi DAS serta nilai kekasaran (n-manning). Ratarata geometri, kekasaran, dan kemiringan aliran antara dua elemen grid tersebut dihitung.

- Kedalaman aliran $\mathrm{dx}$, untuk menghitung kecepatan melintasi batas grid pada timestep berikutnya $(\mathrm{i}+1)$, adalah diperkirakan dari timestep sebelumnya $\mathrm{i}$, menggunakan estimasi linear (rata-rata kedalaman antara dua elemen)

- Debit Q yang melintasi batas grid dihitung dengan mengalikan kecepatan dengan daerah aliran pada potongan melintang. Kenaikan debit untuk timestep di delapan arah aliran ( hulu dan hilir elemen channel) dijumlahkan dan perubahan volume (debit net $\mathrm{x}$ timestep) didistribusikan ke area penyimpanan yang tersedia dalam grid atau saluran elemen untuk menentukan peningkatan kedalaman aliran.

- Kriteria stabilitas numerik diperiksa untuk kedalaman aliran elemen grid baru. Jika salah satu kriteria stabilitas terlampaui, waktu simulasi di reset ke simulasi waktu sebelumnya, kenaikan timestep akan berkurang, semua perhitungan timestep sebelumnya dibuang dan kecepatan perhitungan dimulai lagi.

- Simulasi berlangsung dengan meningkatnya timesteps sampai kriteria stabilitas terlampaui.

2. Ada 5 pemodelan yang dapat dilakukan menggunakan data yang diperoleh (peta topografi dalam format .DXF, curah hujan, pasang surut, dan penampang sungai), yakni:

- Pemodelan menggunakan data hujan (pemodelan 1)

- Pemodelan menggunakan data hujan, penampang saluran, dan tanpa data pasang surut (pemodelan 2)

- Pemodelan menggunakan data hujan, penampang saluran, dan dengan data pasang surut (pemodelan 3)

- Pemodelan menggunakan hidrograf inflow, penampang saluran, dan tanpa data pasang surut (pemodelan 4)

- Pemodelan menggunakan hidrograf inflow, penampang saluran, dan dengan data pasang surut (pemodelan 5)

3. Pemodelan 3 merupakan pemodelan yang paling cocok dijadikan acuan sebagai peta genangan DAS Guring karena menghasilkan plot grid element maximum flow velocity dan Plot maximum velocity (vector) yang realistis dengan menggambarkan adanya pengaruh pasang surut dan tidak adanya pengaruh batasan/boundary hulu (yang memiliki debit inflow tinggi sehingga menghasilkan genangan pada floodplain terkonsentrasi di daerah hulu) dan hilir. Namun secara keseluruhan, kedalaman maksimum genangan berada pada saluran/channel.

4. Hasil pemodelan 2D yang dapat ditampilkan terkait peta genangan adalah sebagai berikut:

- Plot maximum flow depth atau plot final floodplain flow depth: untuk menampilkan daerah kedalaman maksimum genangan. Sedangkan, untuk mengetahui kedalaman maksimum aliran pada saluran dan dataran banjir, dapat dilihat dari hasil plotting max combined channel and floodplain flow depth. Detail dari kedalaman aliran suatu titik dalam DAS Guring dapat dilihat melalui grafik hasil plotting flow depth profile.

- Plot maximum velocity : untuk menampilkan dan mendapatkan hasil kecepatan dan arah aliran pada floodplain dan channel.

- Hazard map : menampilkan resiko terjadinya genangan, yang ditandai dengan perbedaan warna bahaya tingkat tinggi/level 1 (merah), menengah/level 2 (oranye) dan tingkat rendah/level 3 (kuning)

\section{B. SARAN}

1. Perlu adanya penambahan pemodelan dengan input data soil shape dan land use agar hasil pemodelan jauh lebih mendekati pada kondisi real di lapangan.

2. Perlu adanya analisis lebih lanjut terkait penyelesaian dari masalah surging dan konservasi volume, baik dari segi perubahan dimensi channel, nilai n-manning, maupun angka Courant.

3. Perlu data pengukuran lapangan untuk kalibrasi model

\section{DAFTAR PUSTAKA}

[1] FLO-2D Software, Inc. 2009. Data Input Manual

[2] Mamdouh Shahin, H.J.L Van Oorschot, S.J De Lange. 1993. Statistical Analysis in Water Resources Engineering, Rotterdam: Balkema Publishers

[3] Soewarno. 1995. Hidrologi: Aplikasi Metode Statistik untuk Analisis Data, Bandung: NOVA.

[4] Sri Harto Br. 1993. Analisis Hidrologi, Jakarta: Gramedia Pustaka Utama

[5] FLO-2D Software, Inc. 2009. GDS Manual

[6] FLO-2D Software, Inc. 2009. Mapper Manual

[7] FLO-2D Software, Inc 2009. Reference Manual Book 